\title{
City-Suburb Variations In Housing Consumption And Production Patterns \#
}

\author{
RANDOLPH C. Martin* \\ 1. INTRODUCTION
}

This paper presents some empirical evidence relating to differences in housing consumption and production patterns between central cities and suburbs for a small group of U.S. urbanized areas. Richard Muth [8] has observed a strong tendency for the average value of housing consumed per household to increase with distance from the Central Business District (CBD) for a sample of cities. He also finds a negative relationship between the average value of housing produced per square mile and distance for the same group of cities. ${ }^{1}$ The intent here is to determine whether or not these relationships are continuous across corporate boundaries. Are the types of patterns observed for cities also applicable to entire metropolitan areas or is there a tendency for suburbs to have different consumption-distance and production-distance relationships? And, if there are differences, how can they be explained?

In an earlier paper by this author [5], it was observed that population distributions over space tend to vary betwe en cities and suburbs. Specifically, lower central densities and smaller density gradients (the coefficients of population density on distrance) are found for suburbs vis-a-vis central cities. Since housing consumption and production patterns have been shown to be the key components of the relationship between population density and distance for cities," one would expect similar variations between cities and suburbs for these components. Section 2 verifies this expectation and Sections 3 and 4 investigate some hypothesized explanations. It is hoped that this will contribute to a more precise understanding of the factors effecting the distribution of metropolitan residential activity.

\section{ESTIMATION OF PRODUCTION AND CONSUMPTION GRADIENTS}

Utilizing a partial equilibrium model of residential land use, it is possible to predict the relationships between consumption, production and distance from the city-center. Household expenditures on housing are considered to be dependent on housing prices and income. Assuming locational equilibrium for households, it can be shown that the price per unit of housing service must fall over distance (see Muth $[8$, p. 22]). With falling housing prices and a price elasticity of de-

\#Prepared for Presentation at the 1974 Annual Meeting of the Southern Regional Science Association.

*Associate Professor of Economics, University of South Carolina. 
mand greater than one, expenditures on housing can be expected to increase with distance. Differing incomes also contribute through the tendency for higher income households (which consume more housing than their lower income counterparts) to locate at greater distances from the CBD. Basically, this results from housing expenditures rising with income at rates greater than increases in marginal transport costs. ${ }^{3}$ Thus, locational equilibria for higher income groups are expected to be found at more distant locations.

On the other hand, the decline in the value of housing produced per unit of land depends on land rents falling with distance (in response to increasing transport costs). If one assumes that the price of non-land factors of production are invariant with distance, the expectation is for a substitution of land for non-land factors in the production of housing as distance increases. This substitution would then lead to a decline in the intensity (and value) of residential land use per unit of land (see Muth [8, pp. 55-56]).

To quantify these relationships, the following proxy variables for the value of housing output per acre and per household expenditure on housing are defined:

$\mathrm{VL}=$ median value of housing produced in a census tract in dollars per residential acre, per month.

$=[$ (number of units reporting contract rents $\mathrm{x}$ median contract rent) + (number of units reporting values for owner-occupied dwelling $\mathrm{x}$ $1 / 100 \mathrm{x}$ median value of owner-occupied dwellings) $] \div$ (acres of land used for residential purposes in the census tract).

$\mathrm{VH}=$ median value of housing consumed in dollars per household, per month in a census tract.

$=$ (same numerator as VL) $\div$ (number of units reporting contract rent + number of units reporting owner-occupied values).

These variables are as defined by Muth [8, pp. 187-188] with the exception that net residential land area rather than gross (total) land area is used in the denominator of VL. Evidence presented in Martin [4, p. 27] indicates that there exists a consistent variation in the proportion of land used for residential purposes over distance from CBDs. This variation would introduce an extraneous bias into the measurement of the production value-distance relationships if gross land area is used.

Collecting the information for VL and VH for the census tracts of each urbanized area and measuring the straight line distance of each tract from the CBD allows the estimation of production and consumption gradients. " Census tracts are also distinguished as to whether they are within the corporate city ("city" tracts) or outside the city but within the urbanized area ("suburb" tracts). Tracts on the corporate boundary are labeled "city" if over half their population is found to reside in the city. Those lying on the outer boundary of the urbanized area are classified "suburb" if over half of their land area appeared to be inside the boundary line. 
The estimation of gradients and intercepts (calculated values of VL and VH at the $\mathrm{CBD}$ ) is then accomplished by utilizing the following form:

$$
\begin{aligned}
& \mathrm{VL}^{*}=\mathrm{L}^{*}+\mathrm{ak}+\mathrm{S}_{1} \Sigma_{1}+\mathrm{S}_{2} \Sigma_{2} \\
& \mathrm{VH}^{*}=\mathrm{H}^{*}+\mathrm{bk}+\mathrm{S}_{3} \Sigma_{3}+\mathrm{S}_{4} \Sigma_{4}
\end{aligned}
$$

where $\Sigma_{1}=\Sigma_{3}=1$ if suburb tract

0 otherwise

$$
\Sigma_{2}=\Sigma_{4}=\quad \begin{aligned}
& \mathrm{k} \text { if suburb tract } \\
& 0 \text { otherwise }
\end{aligned}
$$

Here, the asterisks represent natural $\log$ values, $\mathrm{k}$ is the straight line distance to the CBD in miles, $\mathrm{L}$ and $\mathrm{H}$ are intercept values, and $\Sigma_{1}, \Sigma_{3}$ and $\Sigma_{2}, \Sigma_{4}$ are the suburban intercept and slope dummy variables. The hypothesis to be tested is whether or not the coefficients $\mathrm{S}_{1}, \mathrm{~S}_{2}, \mathrm{~S}_{3}$ and $\mathrm{S}_{4}$ are significantly different from zero. ${ }^{5}$

Table 1 presents the results of equation (2.1) for the five urban areas. As can be seen, the expected negative relationship between the value of housing produced per acre and distance is quite strong with all five "a" coefficients having negative signs and four being significantly different from zero. Also, the same four areas exhibit significantly different intercepts and gradients for their suburban parts as indicated by the $\mathrm{s}_{1}$ and $\mathrm{s}_{2}$ coefficients. Three of these (Nashville, Portland and San Jose) show smaller suburban intercepts (negative $\mathrm{s}_{1}$ values) and smaller suburban gradients (positive S2 values). In fact, the surburban sections of Portland and San Jose are observed to have small but significant positive gradients $\left(\left|\mathbf{S}_{2}\right|>|\mathrm{a}|\right)$. The results of equation (2.1) for Milwaukee are just the opposite of those for Nashville, Portland and San Jose. Here, the suburban area has a higher intercept value (positive $\mathrm{s}_{1}$ ) and a steeper production value gradient (negative $\mathrm{s} 2$ ):

\section{TABLE 1}

$\mathrm{VL}^{*}$ ON DISTANCE

\begin{tabular}{lccccc}
\hline Urbanized Area & $\mathrm{L}^{*}$ & $\mathrm{a}$ & $\mathrm{S} 1$ & $\mathrm{~S} 2$ & $\mathrm{R}^{2}$ \\
\hline Akron & 6.853 & -.098 & -.016 & -.036 & .27 \\
Milwaukee & 7.581 & $(-1.816)$ & $(-.027)$ & $(-.294)$ & \\
& & $(-8.949)$ & $(4.253)$ & $(-5.850)$ & .62 \\
Nashville & 7.002 & $-.465^{* *}$ & $-1.343^{*}$ & $.389^{*}$ & .36 \\
& & $(-3.113)$ & $(-2.334)$ & $(2.131)$ & \\
Portland & 7.266 & $-.179^{* * *}$ & $-1.248^{* * *}$ & $.197^{* * *}$ & .59 \\
& & $(-7.465)$ & $(-4.838)$ & $(4.706)$ & \\
San Jose & 6.912 & $-.129^{*}$ & $-.608^{* *}$ & $.160^{*}$ & .12 \\
& & $(-2.137)$ & $(-3.026)$ & $(2.572)$ & \\
\hline
\end{tabular}

at values are shown in parentheses

* significant at .05 level of confidence.

**significant at .01 level of confidence

*** significant at .001 level of confidence 
The per household consumption patterns of equation (2.2) can be seen in Table 2. As expected, the per household expenditure and distance relationship (b coefficient) is positive for all five areas with four of these testing out significantly different from zero. A tendency for differences between cities and suburbs is also discernable. The five positive $\mathrm{S}_{3}$ values (three being significantly different from zero) show a trend of higher suburban intercepts and the five negative $\mathrm{s}_{4}$ values (four testing different from zero) indicate differences in consumption gradients between cities and suburbs. For Nashville and San Jose, this takes the form of smaller positive valued gradients for suburbs vis-a-vis central cities $(|b|$ $\left.>\left|\mathrm{S}_{4}\right|\right)$. The results are such for Akron and Milwaukee that their suburban parts reflect a small but significant negative relationship between per household expenditures on housing and distance $\left(|\mathrm{b}|<\left|\mathrm{S}_{4}\right|\right)$.

While it is of course difficult to make any generalized statements from these findings on five urbanized areas, the results of Tables 1 and 2 certainly indicate a very strong possibility that different production and consumption patterns exist between central cities and their suburbs.

TABLE 2

$\mathrm{VH}^{*}$ ON DISTANCE

\begin{tabular}{lccccc}
\hline Urbanized Area & $\mathrm{H}^{*}$ & $\mathrm{~b}$ & $\mathrm{~S} 3$ & $\mathrm{~S} 4$ & $\mathrm{R}^{2}$ \\
\hline Akron & 4.117 & $.209^{* * *}$ & $1.530^{* * *}$ & $-.383^{* * *}$ & .48 \\
& & $(6.197)$ & $(4.048)$ & $(-4.941)$ & \\
Milwaukee & 4.025 & $.166^{* * *}$ & $1.042^{* * *}$ & $-.178^{* * *}$ & .73 \\
& & $(19.771)$ & $(7.370)$ & $(-8.325)$ & \\
Nashville & 3.511 & $.260^{* * *}$ & $.857^{* * *}$ & $-.211^{* * *}$ & .59 \\
& & $(4.197)$ & $(3.595)$ & $(-2.798)$ & \\
Portland & 4.339 & .032 & .357 & -.048 & .10 \\
& & $(1.656)$ & $(1.712)$ & $(-1.413)$ & \\
San Jose & 4.641 & $.087^{* *}$ & .067 & $-.064^{*}$ & .24 \\
& & $(3.109)$ & $(.718)$ & $(-2.226)$ & \\
\hline
\end{tabular}

aSee notes to TABLE 1 .

\section{DIFFERENCES IN CITY-SUBURB \\ CONSUMPTION AND PRODUCTION \\ GRADIENTS}

The model of residential land use briefly discussed at the beginning of the preceeding section suggests three factors which could influence the observed differences in housing production and consumer gradients. On the production side, it will be argued that one can expect steeper production value-distance gradients in older sections of the urbanized area.

To see this argument, it is necessary to state that locational equilibrium at a finite distance requires that

$$
-\mathrm{qp}_{\mathrm{k}}=\mathrm{T}_{\mathrm{k}}
$$


be satisfied (see Muth [8, p. 22]). In this statement $q$ is the quantity of housing consumed by the household, $p_{k}$ is the derivative of price per unit of housing service with distance from the $\mathrm{CBD}$, and $\mathrm{T}_{\mathrm{k}}$ is the derivative of transport costs with respect to distance. Dividing both sides of (3.1) by pq (housing expenditures) yields

$$
-\mathrm{p}_{\mathrm{k}} / \mathrm{p}=\mathrm{T}_{\mathrm{k}} / \mathrm{pq}
$$

Thus, the relative rate of housing price decline with distance $\left(-p_{k} / p\right)$ is directly proportional to marginal transport costs $\left(\mathrm{T}_{\mathrm{k}}\right)$ and inversely proportional to housing expenditures per household (pq).

Since older sections of an urban area were built at a time when transportation costs were undoubtedly a great deal higher than they are now, the value of $T_{k}$ in (3.2) would have been larger and resulted in steeper price gradients during construction. This steeper price gradient (and corresponding rent gradient) would lead to a faster decrease in the value of housing produced per acre over distance from the CBD. Thus, since housing is a rather long-lived good and unable to make rapid adjustments in its intensity per unit of land, it is here argued that production value gradients in older areas will reflect production patterns which occurred during a time of higher transportation costs. If these older areas generally coincide with the corporate city there is reason to expect the steeper production value gradients for central cities observed in Table 1 .

On the consumption side, it will be argued that differences in incomes of residents and differences in tenure status between areas may lead to the variations in household expenditure patterns noted in Table 2. Since higher income households can be expected to spend more on housing than lower income families, the denominator of the right-hand side of (3.2) will be larger. This, in turn, would lead to smaller price gradients in areas housing a predominance of high income consumers. $^{6}$ Since the housing expenditure gradient varies inversely with the price gradient, one then can expect smaller rates of increase in per household expenditures on housing over distance in higher income sections of the urbanized area. If these areas are found predominantly in the suburb, then this effect should be reflected in the estimation of consumption gradients for the suburban parts of the urbanized areas.

The other hypothesis to be tested is the expected influence of federal tax and mortgage programs on consumption patterns. Since the present income tax system fails to impute rental values of owner-occupied housing and allows deductions for mortgage interest and property taxes paid, the effect is to reduce the unit price of owner-occupied housing services relative to rental units. In a similar manner, mortgage insurance programs (VA and FHA) tend to reduce the interest costs for single family, owner-occupied units and thus, also affects relative prices. If the price per unit of housing service, inclusive of these effects, is lower in areas with a large percentage of owner-occupied units, one can then expect larger household expenditures $(p q)$ and smaller price gradients $\left(-\mathrm{p}_{\mathrm{k}} / \mathrm{p}\right)$ than would have been observed exclusive of these effects. Again, this smaller price gradient would lead to a smaller consumption gradient in a manner similar to the pre- 
viously mentioned income effect. To the extent that the city-suburb division generally coincides with rental-owner areas, these programs could also lead to smaller expenditure-distance gradients for the suburbs.

To quantify these values and test for their expected influence on production and consumption gradients, the following variables are defined:

$\mathrm{AG}=$ percent of dwelling units built prior to 1940 in the census tract.

$\mathrm{Y}=$ median family and unrelated individuals income in the census tract.

$\mathrm{OC}=$ percent of total units which are owner-occupied in the census tract.

Values for AG, Y, and $\mathrm{OC}$ by census tracts were derived from U.S. Bureau of the Census [12] data. The degree of owner-occupancy variable (OC) is intended to act as a proxy for the federal programs. The impact of these factors would obviously be greater in areas with high proportions of owner-occupied units.

Table 3 shows median values of these three variables for the city and suburb parts of each urbanized area. These values leave little doubt as to the claim that the suburban areas can be characterized as having newer dwellings, higher incomes, and higher degrees of owner occupancy than the central cities. On the average the suburbs have 32 percentage points fewer units built prior to 1940 , about a $\$ 1400$ higher median income and a 21 percentage point higher degree of owner occupancy. Thus, to the extent that these differences are required to explain city-suburb gradient variations, Table 3 provides ample evidence of the existence of the same.

\section{TABLE 3}

MEDIAN VALUES FOR AG, Y, AND OC: CITY AND SUBURB

\begin{tabular}{|c|c|c|c|c|c|c|}
\hline \multirow{2}{*}{$\begin{array}{l}\text { Urbanized } \\
\text { Area }\end{array}$} & \multicolumn{3}{|c|}{ CITY } & \multicolumn{3}{|c|}{ SUBURB } \\
\hline & $\mathrm{AG}$ & $\mathrm{Y}$ & $\mathrm{OC}$ & $\mathrm{AG}$ & $Y$ & $\mathrm{OC}$ \\
\hline Akron & .81 & $\$ 5478$ & .59 & .50 & $\$ 6294$ & .76 \\
\hline Milwaukee & .77 & 5685 & .39 & .47 & 7244 & .72 \\
\hline Nashville & .75 & 2735 & .35 & .36 & 5819 & .74 \\
\hline Portland & .76 & 4790 & .60 & .38 & 5554 & .72 \\
\hline San Jose & .41 & 5715 & .61 & .22 & 6534 & .62 \\
\hline Average & .70 & $\$ 4881$ & .50 & .38 & $\$ 6289$ & .71 \\
\hline
\end{tabular}

To test for the existence of the age of dwelling influence on production gradient differences and income and degree of owner-occupancy effects on consumption gradients, the follwing regression equations were estimated:

$$
\begin{aligned}
& \mathrm{VL}^{*}=\mathrm{L}^{*}+\mathrm{ak}+\mathrm{s}_{1} \Sigma_{1}+\mathrm{s}_{2} \Sigma_{2}+\mathrm{cAG} \\
& \mathrm{VH}^{*}=\mathrm{H}^{*}+\mathrm{bk}+\mathrm{s}_{3} \Sigma_{1}+\mathrm{s}_{4} \Sigma_{2}+\mathrm{dY}+\mathrm{eOC}
\end{aligned}
$$


The formulation of (3.3) allows one to observe the impact of holding constant variations in age of dwellings over tracts of different per acre production values on the differences in city-suburb production gradients. If this variable has the influence that is expected, its inclusion should reduce the size and significance of the suburban dummy coefficients ( $\mathrm{s}_{1}$ and $\mathrm{s}_{2}$ ) and therefore, differences between cities and suburbs. In a similar manner, (3.4) adds $\mathrm{Y}$ and $\mathrm{OC}$ to equation (2.2) for the purpose of testing the effect of these factors on consumption gradients.

The results of estimating (3.3) for each of the five urbanized areas are presented in Table 4. These are found in the second row of each area. The first rows repeat the findings of (2.1) for comparative purposes. It was indicated earlier that one should observe positive values for the AG coefficient (higher valued output per acre in older areas). This generally holds, with four of the five c coefficients exhibiting positive signs and two of these being significantly different from zero. Only Milwaukee shows a negative (and significant) AG coefficient.

\section{TABLE 4}

VL* ON DISTANCE AND AGE OF DWELLINGS ${ }^{a}$

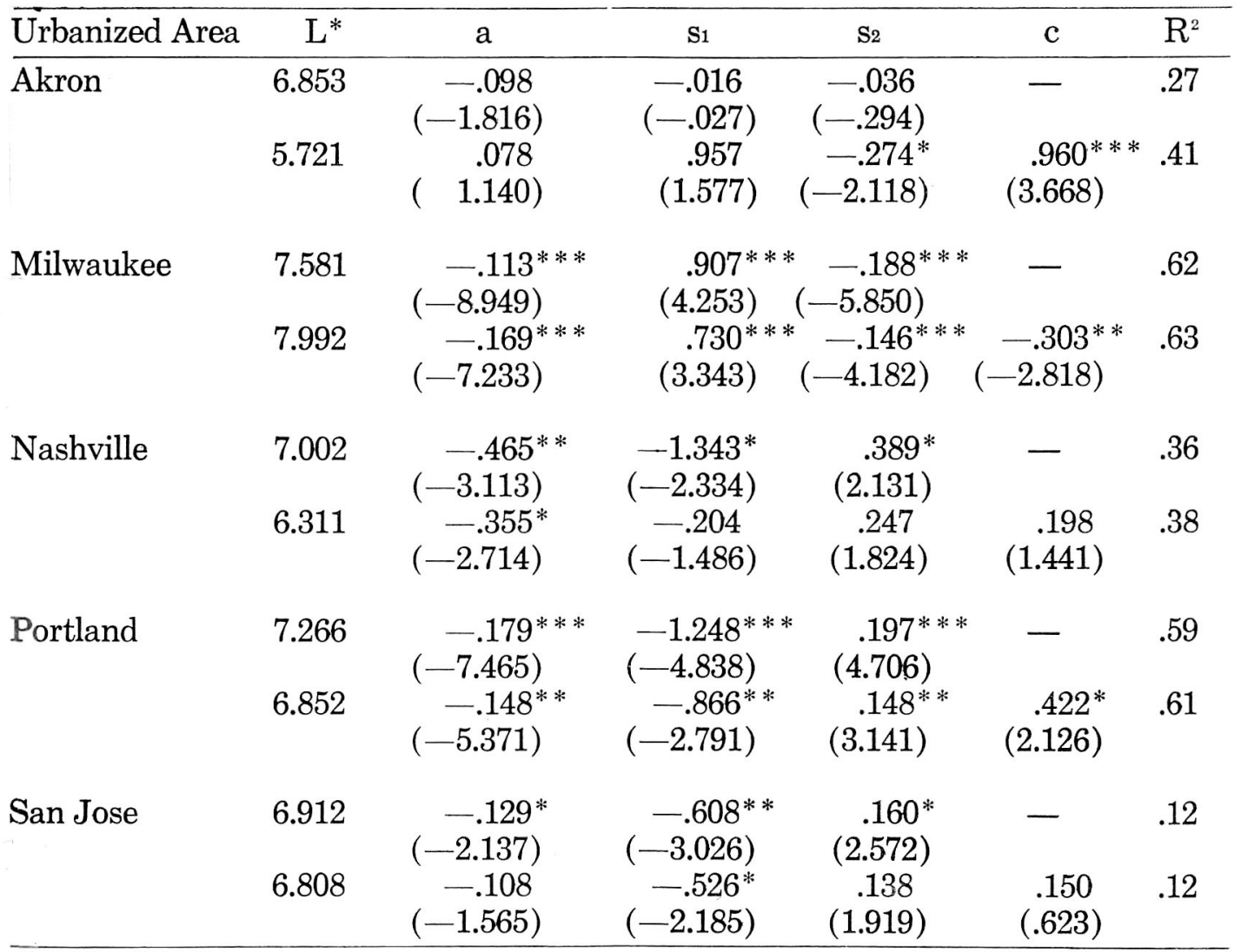

aSee notes to TABLE 1. 
Inclusion of AG also has a noticeable effect on the suburban dummy values. Estimation of (2.1) produced four negative $s_{1}$ coefficients, three of which were significantly different from zero. After inclusion of AG, only three remain negative with two coefficients retaining significance. Turning to the suburban slope dummy, $\Sigma_{2}$, regression (3.3) yields the same three positive $s_{2}$ coefficients, but now it is found to be signifcant only for Portland. Significant negative relationshipps are noted for Akron and Milwaukee. Finally, for the two areas which retain the differences in gradients (Milwaukee and Portland), these differences have been reduced in size by the inclusion of AG. The $\mathrm{S}_{1}$ and $\mathrm{s}_{2}$ values are smaller (with lower $t$ values) in the (3.3) regressions for these urbanized areas.

Table 5 reports the findings of estimating equation (3.4). As in Table 4, the first rows are the values of the distance coefficients without the new variables and the second include the new coefficients. The expectation is for positive relationships between $\mathrm{VH}^{*}$ and both $\mathrm{Y}$ and $\mathrm{OC}$. That is, one expects larger household expenditures in higher income areas and the same for owner occupied areas (due to the homeowners bias in the aforementioned federal programs). These expectations are well documented by the five positive and significant income coefficients (d) and the five positive (three significant) degree of owner occupancy coefficients (e). The results of these findings may be somewhat confused, however, by a rather strong positive intercorrelation between Y and OC. This interdependency will be discussed later, but at this point it is necessary to warn against strict interpretation of the positive e values as resulting solely from federal tax and mortgage programs.

This interdependency should not influence the effect of including $\mathrm{Y}$ and $\mathrm{OC}$ on the suburban dummy variables. Comparing the $\mathrm{s}_{3}$ and $\mathrm{s}_{4}$ values of Table 5 before and after these inclusions indicates a real reduction in consumption gradient differences between cities and suburbs. The intercept coefficient $\left(\mathrm{S}_{3}\right)$ remains positive in three cases, significantly so in only one (Milwaukee). Similarly, the S4 values are now found to be negative for three areas and Milwaukee is the only urbanized area for which the negative coefficient retains its significance. Also, the size of the dummy coefficients and their degree of significance ( $t$ values) have been reduced by holding constant the values of $\mathrm{Y}$ and OC.

The evidence of (3.3) and (3.4) as presented in Tables 4 and 5 seems fairly consistent with previously stated expectations. The observed reduction in citysuburb differences in production gradients lends credence to the belief that the steeper city gradients result from the fact that these units were constructed during periods when transportation costs exceeded those existing when the suburban areas were built. Although there is some difficulty in separating the effects, income and degree of owner-occupancy seem quite important in explaining consumption gradient differences. It would appear, however, that the strongest effect is coming from the income variable. That is, that higher income suburban households spending more on housing than their lower income city-dwelling counterparts leads to smaller price gradients and flatter consumption gradients for this area. 
TABLE 5

$\mathrm{VH}^{*}$ ON DISTANCE, INCOME AND DEGREE OF OWNER OCCUPANCYa

\begin{tabular}{|c|c|c|c|c|c|c|c|}
\hline Urbanized Area & $\mathrm{H}^{*}$ & $\mathrm{~b}$ & $\mathrm{~S} 3$ & $\mathrm{~S}_{4}$ & d & $\mathrm{e}$ & $\mathrm{R}^{2}$ \\
\hline \multirow[t]{2}{*}{ Akron } & 4.117 & $\begin{array}{l}.209 * * * \\
(6.197)\end{array}$ & $\begin{array}{l}1.530^{* * *} \\
(4.048)\end{array}$ & $\begin{array}{l}-.383^{* * *} \\
(-4.941)\end{array}$ & - & - & .48 \\
\hline & 3.476 & $\begin{array}{l}-.006 \\
(-.310)\end{array}$ & $\begin{array}{c}.283 \\
(1.665)\end{array}$ & $\begin{array}{c}-.048 \\
(-1.279)\end{array}$ & $(12.581)^{.0002^{* * *}}$ & $\begin{array}{c}.260^{*} \\
(2.367)\end{array}$ & .92 \\
\hline \multirow[t]{2}{*}{ Milwaukee } & 4.025 & $\begin{array}{c}.166^{* * * *} \\
(19.771)\end{array}$ & $\begin{array}{l}1.042^{* * * *} \\
(7.370)\end{array}$ & $\begin{array}{c}-.178^{* * *} \\
(-8.325)\end{array}$ & - & - & .73 \\
\hline & 3.766 & $\begin{array}{l}.053^{* * *} \\
(4.911)\end{array}$ & $\begin{array}{l}.401^{* * *} \\
(3.526)\end{array}$ & $\begin{array}{l}-.070^{* * *} \\
(-3.982)\end{array}$ & $\begin{array}{l}.0001^{* * *} \\
(4.663)\end{array}$ & $\begin{array}{l}.661^{* * *} \\
(7.351)\end{array}$ & .86 \\
\hline \multirow[t]{2}{*}{ Nashville } & 3.511 & $\begin{array}{l}.260^{* * *} \\
(4.197)\end{array}$ & $\begin{array}{l}.857^{* * *} \\
(3.595)\end{array}$ & $\begin{array}{l}-.211^{* * *} \\
(-2.798)\end{array}$ & - & - & .59 \\
\hline & 3.358 & $\begin{array}{c}.056 \\
(.942)\end{array}$ & $\begin{array}{c}.231 \\
(1.076)\end{array}$ & $\begin{array}{c}-.080 \\
(-1.288)\end{array}$ & $\begin{array}{l}.0002^{* * *} \\
(6.833)\end{array}$ & $\begin{array}{c}.072 \\
(.297)\end{array}$ & .80 \\
\hline \multirow[t]{2}{*}{ Portland } & 4.339 & $\begin{array}{c}.032 \\
(1.656)\end{array}$ & $\begin{array}{c}.357 \\
(1.612)\end{array}$ & $\begin{array}{c}-.048 \\
(-1.413)\end{array}$ & - & - & .10 \\
\hline & 3.602 & $\begin{array}{l}-.073^{* * *} \\
(-4.731)\end{array}$ & $\left(-.274^{*}\right.$ & $\begin{array}{l}.077^{* *} \\
(3.361)\end{array}$ & $\begin{array}{l}.0002^{* * *} \\
(9.501)\end{array}$ & $\begin{array}{c}.150 \\
(1.150)\end{array}$ & .72 \\
\hline \multirow[t]{2}{*}{ San Jose } & 4.641 & $\begin{array}{l}.087^{* * *} \\
(3.109)\end{array}$ & $\begin{array}{c}0.67 \\
(.718)\end{array}$ & $\begin{array}{r}-.064^{*} \\
(-2.226)\end{array}$ & - & - & .24 \\
\hline & 4.161 & $\begin{array}{l}.008 \\
(.501)\end{array}$ & $\left(-2.119^{*}\right.$ & $\begin{array}{c}.012 \\
(.696)\end{array}$ & $\begin{array}{l}.0004^{* *} \\
(2.775)\end{array}$ & $\begin{array}{l}.654^{* * *} \\
(5.764)\end{array}$ & .77 \\
\hline
\end{tabular}

aSee footnotes to TABLE 1. 


\section{SOME FURTHER EVIDENCE AND CONSIDERATIONS}

As further evidence of the above effects, Table 6 shows the regression coefficients and coefficients of determination for the least squares regressions of distance from the CBD on each of the other independent variables ( $\mathrm{AG}, \mathrm{Y}, \mathrm{OC}$ ). Results are shown for the central city and suburb sections of the urbanized areas. By comparing these values with the findings of Section 2, certain observations can be made which support the hypothesized explanations of gradient differences. First, when distance is regressed against age of dwellings for the five central cities, all but Nashville have fairly large negative and highly significant coefficients. With the exception of Akron (where the AG coefficient is significant but no significant production gradient is observed) and Nashville (where the reverse is true), these results correspond quite well with the negative production value per acre gradients of Table 1.

Turning to the suburban results, it is interesting to note that only for Milwaukee does there exist a significant negative relationship between distance and dwelling age. This value is quite large (twice as large as the city coefficient) and in Table 1, Milwaukee is the only urbanized area with a negative and significant s2 coefficient (i.e., a steeper production value gradient for the suburb). The remaining suburban coefficients are positive but do not test to be different from zero. However, the positive coefficients for Portland and San Jose are fairly large and close to being significant. Table 1 shows that these suburban areas are the only two for which the production gradient is positive $\left(\left|\mathbf{S}_{2}\right|>|\mathbf{a}|\right)$.

The results of running distance on medium income and degree of owner occupancy also provide some insight into the findings of Section 2. The significant and positive $\mathrm{Y}$ and $\mathrm{OC}$ coefficients of Table 6 for the cities of Akron, Milwaukee, Nashville and San Jose correspond with the positive consumption gradients noted for these areas in Table 2. And, even though the Portland findings of Table 6 do not support the lack of significance noted for this city in Table 2, the signs are correct and the values in Table 2 are quite close to being significantly different from zero.

The results of these simple regressions for the suburban areas can generally be characterized by their lack of significance. Akron's suburb has a negative and significant $\mathrm{Y}$ coefficient and a negative (but insignificant) $\mathrm{OC}$ coefficient. This supports the relatively large negative consumption gradient for the Akron suburb observed in Table 2. $(.209-.388=-.174)$. The negative (but insignificant) $\mathrm{Y}$ coefficient for Milwaukee corresponds with its small negative suburban consumption gradient, and the positive and significent $O C$ coefficient for Nashville also supports the results of Table 2 for this suburban area. Finally, the positive and nearly significant $Y$ coefficient for the San Jose suburb matches its positive consumption gradient found in Table 2.

Considering these comparisons, more often than not the simple relationships between distance and each of the other explanatory variables for cities and suburbs correspond to the differences in production and consumption gradients. While this by itself does not indicate cause and effect, it does provide support for 
TABLE 6

DISTANCE ON AGE OF DWELLINGS, INCOME AND DEGREE OF OWNER OCCUPANCY: CITY AND SUBURB ${ }^{a}$

\begin{tabular}{|c|c|c|c|c|c|c|c|c|c|c|c|c|}
\hline \multirow{2}{*}{$\begin{array}{c}\text { Urbanized } \\
\text { Area }\end{array}$} & \multicolumn{6}{|c|}{ CITY } & \multicolumn{6}{|c|}{ SUBURB } \\
\hline & AC coef. & $\mathrm{R}^{2}$ & Y coef. & $\mathrm{R}^{2}$ & OC coef. & $\mathrm{R}^{2}$ & AG coef. & $\mathrm{R}^{2}$ & Y coef. & $\mathrm{R}^{2}$ & OC coef. & $\mathrm{R}^{2}$ \\
\hline Akron & $\begin{array}{l}-3.120 * * * \\
(-7.935)\end{array}$ & .57 & $\begin{array}{l}.0004^{* * *} \\
(6.224)\end{array}$ & .45 & $\begin{array}{l}3.668^{* * *} \\
(6.802)\end{array}$ & .50 & $\begin{array}{l}1.413 \\
(.890)\end{array}$ & .09 & $\begin{array}{l}-.0007^{*} \\
(-2.549)\end{array}$ & .45 & $\begin{array}{c}-3.076 \\
(-1.324)\end{array}$ & .18 \\
\hline Milwaukee & $\begin{array}{l}\mathrm{e}-3.950^{* * * *} \\
-20.781)\end{array}$ & .73 & $\begin{array}{l}.0010^{* * * *} \\
(16.177)\end{array}$ & .62 & $\begin{array}{c}6.058^{* * *} \\
(18.616)\end{array}$ & .78 & $\begin{array}{c}-7.994^{*} \\
(-2.376)\end{array}$ & .36 & $\begin{array}{c}-.003 \\
(-.595)\end{array}$ & .03 & $\begin{array}{c}5.630 \\
(1.076)\end{array}$ & .10 \\
\hline Nashville & $\begin{array}{c}-1.397 \\
(-1.873)\end{array}$ & .09 & $\begin{array}{l}.0005^{* * *} \\
(6.031)\end{array}$ & .53 & $\begin{array}{l}2.764^{* * *} \\
(8.669)\end{array}$ & .43 & $\begin{array}{c}.062 \\
(.030)\end{array}$ & .00 & $\begin{array}{r}.0003 \\
(1.613)\end{array}$ & .13 & $\begin{array}{l}9.404^{* *} \\
(3.872)\end{array}$ & .24 \\
\hline Portland & $\begin{array}{l}-6.243^{* * * *} \\
(-7.378)\end{array}$ & .46 & $\begin{array}{l}.0008^{* * * *} \\
(6.031)\end{array}$ & .36 & $\begin{array}{l}4.767^{* * *} \\
(8.669)\end{array}$ & .54 & $\begin{array}{c}2.446 \\
(1.763)\end{array}$ & .11 & $\begin{array}{c}-.002 \\
(-.776)\end{array}$ & .02 & $\begin{array}{c}-3.998 \\
(-1.457)\end{array}$ & .08 \\
\hline San Jose & $\begin{array}{l}-3.356^{* * *} \\
(-4.586)\end{array}$ & .47 & $\begin{array}{l}.0050^{* * *} \\
(3.374)\end{array}$ & .32 & $\begin{array}{l}4.339 * * \\
(3.508)\end{array}$ & .34 & $\begin{array}{c}3.409 \\
(1.218)\end{array}$ & .03 & $\begin{array}{r}.0008 \\
(1.961)\end{array}$ & .07 & $\begin{array}{c}-.984 \\
(-.045)\end{array}$ & .00 \\
\hline
\end{tabular}

aSee notes to TABLE 1. 
the conclusions of Section 3. The degree of this correspondence is simply too great to ascribe solely to chance.

The final question to be answered is to what extent can the simple relationships between each of the three explanatory variables (AG, Y, and $\mathrm{OC}$ ) and distance from the CBD be attributed to the intercorrelation of these variables? In particular, it was previously noted that there exists a rather strong correlation between income and degree of owner occupancy. To what extent is the positive income-distance relationship attributable to the preference of higher income households for owner-occupied units? Table 7 shows the simple correlation coefficients between $\mathrm{Y}$ and $\mathrm{k}$ and the partial correlation coefficients between $\mathrm{Y}$ and the remaining explanatory variables. Since the major concern is now with the closeness of association, correlation coefficients are shown rather than elasticities or regression coefficients.

The simple correlation coefficients of course reaffirm the previous finding of a strong positive association between median income and distance in the central city part of each urbanized area. For all five cities, the simple correlation coefficient (shown on the first line for each area) between $\mathrm{Y}$ and $\mathrm{k}$ is significantly positive and quite large. When AG and $\mathrm{OC}$ are added, as shown on the second line for each area, the partials between $\mathrm{k}$ and $\mathrm{Y}$ for the central cities are all distinctly smaller. Indeed, the positive association between income and distance for the cities appears to be coming from both a strong preference by higher income households for newer units (three negative and significant AG coefficients) and for owner occupied units (five positive and significant OC coefficients)..$^{7}$ Only the cities of Milwaukee and Nashville retain the significantly positive relationship between income and distance once the effects of dwelling age and agree of owner occupancy are held constant. Also, with the exception of these two cities, a substantially larger fraction of the income variance between tracts is explained by adding $\mathrm{AG}$ and $\mathrm{OC}$ as shown by the $\mathrm{R}^{2}$ values in the last column of the city section of Table 7 .

Turning to the results for the suburban parts of the urbanized areas, one again notes very little correlation between income and distance. The only value found to be significantly different from zero is a negative coefficient for the Akron suburb. However, there is some indication that a similar though less pronounced preference by higher income households for newer and owner occupied dwellings also exists in the suburban areas. This is evidenced by the four negative (one significantly so) AG coefficients and the five positive (one significantly different from zero) OC coefficients found in the suburban part of Table 7. And again, a much higher fraction of the variance in income among suburban tracts is explained after including $\mathrm{AG}$ and $\mathrm{OC}$.

The tentative conclusions reached from the above observations are first, that at least for three of the central cities (Akron, Portland and San Jose) the positive income-distance relationship can be explained in terms of strong preferences by higher income households for both newer and owner occupied housing units. Secondly, it appears that for the suburban areas income is not generally associated with distance because neither dwelling age or degree of owner occupancy is 


\section{TABLE 7}

SIMPLE AND PARTIAL CORRELATION COEFFICIENTS OF INCOME WITH DISTANCE, AGE OF DWELLINGS AND DEGREE OF OWNER-OCCUPANCY: CITY AND SUBURB ${ }^{\mathrm{b}}$

\begin{tabular}{|c|c|c|c|c|c|c|c|c|}
\hline \multirow[b]{2}{*}{ Urbanized Area } & \multicolumn{4}{|c|}{ CITY } & \multicolumn{4}{|c|}{ SUBURB } \\
\hline & $\mathrm{k}$ & $\mathrm{AG}$ & OC & $\mathrm{R}^{2}$ & $\mathrm{k}$ & $\mathrm{AG}$ & $\mathrm{OC}$ & $\mathrm{R}^{2}$ \\
\hline Akron & $\begin{array}{r}.67^{*} \\
-.07\end{array}$ & $-\overline{50} *$ & $\overline{.59^{*}}$ & $\begin{array}{l}.45 \\
.71\end{array}$ & $\begin{array}{l}-.67^{*} \\
-.60\end{array}$ & $-\overline{16}$ & $\overline{.54}$ & $\begin{array}{l}.45 \\
.75\end{array}$ \\
\hline Milwaukee & $\begin{array}{l}.79^{*} \\
.38^{*}\end{array}$ & $\overline{.}^{*}$ & $\overline{.62} *$ & $\begin{array}{l}.62 \\
.77\end{array}$ & $\begin{array}{l}-.18 \\
-.06\end{array}$ & $\overline{.25}$ & $\overline{.37}$ & $\begin{array}{l}.03 \\
.20\end{array}$ \\
\hline Nashville & $\begin{array}{l}.72^{*} \\
.54^{*}\end{array}$ & $\overline{.17}$ & $\overline{.33^{*}}$ & $\begin{array}{l}.53 \\
.59\end{array}$ & $\begin{array}{l}.36 \\
.24\end{array}$ & $-\overline{35}$ & $\overline{.23}$ & $\begin{array}{l}.13 \\
.38\end{array}$ \\
\hline Portland & $\begin{array}{c}.60^{*} \\
-.18\end{array}$ & $-.34^{*}$ & $\overline{.72^{*}}$ & $\begin{array}{l}.36 \\
.72\end{array}$ & $\begin{array}{r}-.15 \\
.14\end{array}$ & $-\overline{49}$ & $\overline{.34}$ & $\begin{array}{l}.02 \\
.55\end{array}$ \\
\hline San Jose & $\begin{array}{l}.57^{*} \\
.06\end{array}$ & $-\overline{.54^{*}}$ & $\overline{.51^{*}}$ & $\begin{array}{l}.32 \\
.73\end{array}$ & .27 &.$- \overline{65}$ &.$\overline{68^{*}}$ & $\begin{array}{l}.07 \\
.82\end{array}$ \\
\hline
\end{tabular}

${ }^{b}$ Asterisks denote significance at least at the .05 level of confidence 
highly correlated with distance (see Table 6). Thus, the differences in consumption gradients between cities and suburbs noted in Section 3 may be at least partially explained by the observation that suburban development patterns have not followed the central city patterns (higher concentrations of older and rental units closer to the CBD.)

\section{SUMMARY AND CONCLUSIONS}

The initial purpose of this paper was to determine whether or not previously observed housing production and consumption gradients for U.S. cities are continuous across corporate boundaries. For a small group of urbanized areas, Section 2 observed that differences do seem to exist. To explain these differences, Section 3 proposes that higher transport costs during construction would lead to different production gradients in older parts of an urbanized area (e.g., central city). It was also suggested that since higher income households generally spend more on housing than low income families and federal programs tend to favor owner occupancy, different consumption gradients might be observed in areas with concentrations of high income inhabitants and owner occupied dwellings. To test for the existence of such influences, an age of dwelling variable was included in the production value regressions and income and owner occupancy variables were added to the expenditure regressions. In both situations, the size and significance of the suburban dummy variables were noticeably reduced, indicating that the expected effects of these factors may be present.

To further check these conclusions, Section 4 first observes that while strong elasticities between distance and each of the explanatory variables are observable for the central cities, such relationships do not in general exist for the suburban areas. And, where they do appear, their expected influence on consumption or production patterns had been observed in Section 2. Finally, it was noted that for central cities there exists a fairly strong positive association between income and degree of owner occupancy and a negative association between income and age of dwellings. These intercorrelations were found to be the major reason for the previously observed income-distance relationship. Some evidence appeared to indicate that suburbanites have similar preferences, but since neither dwelling age or degree of owner occupancy were highly correlated with distance, income also was found to be unrelated to distance from the CBD.

The findings of this paper are that production and consumption patterns do differ between the city and suburban parts of urbanized areas and that the bulk of this variance can be explained in terms of differences dwelling age, income and degree of owner occupancy between the two areas. It also apears that the neat residential development pattern which has occurred in central cities is not being continued into the suburban areas. One does not in general find the oldest areas of the suburb being closest to the CBD and the newer sections further away. Because of this and the observed preferences for newer dwellings, it would seem that the consumption gradient differences may partially be resulting from these random development patterns. Differences in the distribution of dwellings over distance between the two areas could result from either transportation costs fall- 


\section{ing dramatically relative to other costs or a decrease in the importance of the CBD as an employment and consumption center, or a combination of these factors.}

\section{FOOTNOTES}

1See specifically Tables 2 and 3 of [8, pp. 190-191]. The 'gradients' of these regressions are stated in terms of their influence on population density gradients. Thus, a positive value for the consumption gradient reflects a positive consumption-distance relationship and a positive value for the production gradient indicates a negative relationship between production value per square mile and distance.

2The components of the log-linear density gradient can be expressed as:

$$
\mathrm{g}=\mathrm{d} / \mathrm{dk}(\mathrm{P} / \mathrm{L}) *=\mathrm{d} / \mathrm{dk}(\mathrm{P} / \mathrm{H}) *+\mathrm{d} / \mathrm{dk}(\mathrm{pQ} / \mathrm{L}) *-\mathrm{d} / \mathrm{dk}(\mathrm{pQ} / \mathrm{H})
$$

See Muth [8, p. 185]. The last two elements on the right-hand side of this identity indicates that density varies over distance $(k)$ directly with the variation in the value of housing produce per unit of land (pQ/L) and inversely with the variation in housing expenditures per household $(\mathrm{pQ} / \mathrm{H})$. Chapter 8 of [8] deals with the importance of these two components to the variation of population density with distance.

3 Or the real income elasticity of demand for housing is greater than the elasticities of total and marginal transport costs with respect to the wage rate. See Muth [8, p. 31].

${ }_{4}^{4}$ Due to the lack of available information on residential area by census tracts and contract rent for some of the more distance tracts, gradients are estimated for only five urbanized areas. These are: Akron, Ohio; Milwaukee, Wisconsin; Nashville, Tennessee; Portland, Oregon; and San Jose, California. The sources of residential land area (in acres) by tracts for these areas can be found in (1), (2), (6), (7), (9), and (10). All other data are from U.S. Bureau of Census (12). Straight line distance (in miles) was measured from the center of each tract to the center of the CBD using the tract maps.

5The suburban intercept value of (2.1), for example, would be $L^{*}( \pm) \mathbf{s}_{1}$ and the suburban gradient would be a $( \pm)$ s. The use of dummy variables at this point is the same as estimating separate regressions for the two parts of the urbanized area. See Goldberger [3, pp. 224-226]. However, where other variables are added, the result is to require their coefficients to be the same in the two regressions and gains are made in degrees of freedom.

6Marginal transport costs $\left(T_{k}\right)$ would also be higher due to greater opportunity costs of time spent in travel. It seems unlikely, however, that this would completely cancel the income effect on price gradients. See Muth [8, pp. 31-32].

7One should note the rather small but significant positive AG coefficient for Milwaukee. There is then some indication of preferences by higher income families in this city for older units.

\section{REFERENCES}

1. Akron Metropolitan Area Transportation Study, Akron, Ohio. 1963 Residential and Gross Land Area by Census Tract for the AMATS Area.

2. Department of City Development, Milwaukee, Wisconsin. Summary of Land Use by Census Tract, 1962.

3. Goldberger, A. S., Econometric Theory. New York: John Wiley and Sons, Inc., 1966.

4. Martin, R. C., "Differentials in the Indensity of Residential Land Use Between Cities and Suburbs," unpublished Ph.D. dissertation, Washington University, St. Louis, Missouri, 1971.

5. - "Spatial Distributions of Population: Cities and Suburbs," Journal of Regional Science, Volume 13, No. 2, 1973, pp. 269-278.

6. Metropolitan Planning Commission. Nashville and Davidson County, Tennessee. "Residential and Total Land Use by Census Tracts, 1966-67," Metropolitan Planning Commission Land Use Study.

7. Metropolitan Planning Commission. Portland, Oregon. Growth Factors: 1960-1980, 1962.

8. Muth, R. F., Cities and Housing. Chicago: The University of Chicago Press, 1969.

9. Planning Department, County of Santa Clara, California. Computer print-out of 1965 land use study data for Census Tract.

10. Southeastern Wisconsin Regional Planning Commission. Waukesha, Wisconsin. 1967 Land Use UpdateLand Use by Civil Division Between Years 1963 and 1967.

11. United States Bureau of Census. 1963 Census of Business. III. Part 1, pp. 2-1 and 11-1, Part 2, pp. 611, 65-1, 80-1, 92-1 and 103-1.

12. Eighteenth Census of the United States: 1960. Population and Housing. Reports \#2, 92, 99, 121, 138; Tables H-1 and H-2. 